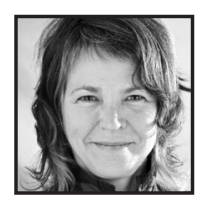

\title{
The Digital Shrine: Community-Engaged Art and Sharing of Memory With Seniors
}

\author{
Patti Fraser, Simon Fraser University
}

\begin{abstract}
This narrative reflects on the artist's involvement in two separate community-engaged art projects: a public event created to memorialize the dead and a digital storytelling project at a Seniors Centre in North Vancouver, B.C. Through a personal arts-based inquiry into ritual and memory, the two projects merge and begin to inform the artist's work with seniors. The inquiry helps to deepen a sense of shared community and to define what a genuine community-engaged practice may be. This article inquires into why art matters in community-engaged work and how creative practice can create new structures of learning and deepen bonds within community.
\end{abstract}

1 $y$ the end of October in Vancouver, British Columbia, the trees are showing their skeletal branches as the moody and unpredictable skies summon winds that blow in a new direction and rain falls unexpectedly. The warmth of early fall gives way to frost as the harvest moon brings with it a sense of the great turning. In Vancouver's Mountain View Cemetery, a celebration of candlelight and fire illuminates the growing darkness at The Night for All Souls. During the past decade, most years at this time I walk the enormity of this cemetery at dusk. Some years helping to light the shrines that are scattered throughout the space, other years to replace burnt-out candles or refresh flower garlands in order to make ready for the quiet groups of visitors who will come once darkness descends to visit this place.

This newly found tradition of tending shrines and memorials to the dead was initiated in the fall of 2005 after my father's death, when I was invited by friend and community-engaged artist Marina Szjarto to create a personal shrine to commemorate 
his death. That first year my shrine was a simple cloth lantern with a picture of my father and a poem that flickered amongst many simple shrines illuminating the darkness at The Night for All Souls.

This was the first year of a new public event created by co-artistic directors Paula Jardine and Marina Szijarto. Small personal shrines are built collectively in workshops during the month of October by anyone who chooses to come and make them. These shrines, along with larger memorials created by artists, illuminate the darkness each night for a week. The public is invited to reflect, add to the shrines, or wander through the cemetery on a journey of reflection where music and memory fill the night. This community-engaged event was intended to help to create collective ways to celebrate and create memorials for the dead through their own work, through commissioning other artists to create memorials, and through the invitation to the public to create small shrines. The Night for All Souls is the current expression of Paula Jardine and Marina Szjarto's artistic collaborations creating celebration events that are public and contemporary expressions of ritual. Marina Szjarto and Paula Jardine's work has, over the course of their careers, explored the values associated with tradition and notions of continuity in ritual-based work.

Clarke Mackey (2010) theorizes the making of art by hand and in community as an extension of the development of a vernacular culture. The vernacular is that which was homemade, or homebred, and derived from the commons. Vernacular art, in Mackey's terms, resides outside of consumer culture and is not made to be bought or sold on the market. Mackey writes about the value of vernacular art, and the erosion of the homemade, local, participatory craft and ritual by standardized products fashioned by trained professionals that are then put up for sale.

At Mountainview Cemetery, the making and reconstituting of ritual and tradition through the making by hand of objects and the making with others in communityengaged settings is an expression of vernacular art. Creating rituals that ask for the community to care for the dead, and in the doing, re-invoke our collective recollections of the past, is an expression of our common need to memorialize and care for the dead. The hand of maker is seen in all of the aspects of work created in The Night for All Souls.

The activism around reconfiguring our responses to death and bringing death and dying back under the domain of the personal, creative, and familial and out of the hands of commercial institutions is thought of by Marina Szjarto and Paula Jardine as part of their work as artists. While traditions like these are enacted in cultures around 
the world, what makes this work art for "social change" is the evocation of vernacular art in multicultural settings and in places where tradition is being re-invented and re-constituted.

\section{The Arts Health and Seniors Digital Storytelling Project}

In that first year of The Night for All Souls, when I made the simple lantern shrine as a way to commemorate the passing of my father, I had returned to my tenure as artist in residence in the Arts, Health, and Seniors Project. This project was composed of four sites of research where community-engaged artists worked with seniors on art projects in order to study the effects of creative practice and art making on the health and well-being of seniors. Vancouver Coastal Health, the City of Vancouver Parks Board Office of Art and Culture, and the University of British Columbia Faculty of Nursing formed a partnership to fund and support this project. Media educator Corin Browne and I were commissioned to create a digital storytelling project at the Silver Harbour Seniors Recreational Centre in North Vancouver as a part of this project. Corin Browne and I share a long history of media education projects primarily with youth. In the first year of our four-year residency, we were discovering the unique challenges of educating and mentoring seniors in the art of storytelling through digital technology in a community-engaged practice.

Some of the participants, those least elderly, while thrilled with their growing mastery over the difficult mediums, and excelling at learning editing programs, were reluctant to spend precious time at the computers sharing their newfound skills with others. The culture of sharing information and skills, which is so much a part of the digital culture of youth, was not replicated in this culture of older adults at Silver Harbour. Many of the participants did not want to engage with media at all and wanted others to engage entirely with the technology and not with each other. Very few wanted to learn camera and sound. With the challenges of this difficult medium, combined with the age of the participants, it was proving difficult to establish a creative inquiry they shared as a community. While the participants were individually pleasant and cooperative, it was proving challenging to develop a collaborative or collective view into what was of vital interest in their current lives. I viewed this form of creative inquiry as a critical part of my role as community-engaged artist, as I was responsible for working with the seniors on the development of story. I did not see my role simply as a teacher of technical skills, but rather as an agent who, through creating hospitable environments, attempts to co-create artistic work with community. 
The challenges and experiences inherent in creative collaborative work, given the right facilitation, have the capacity to strengthen the bonds between the participants and the bonds within the communities they share.

Yet, during that first year at Silver Harbour, while all participant were understandably immersed in producing their own story, with a great deal of help from younger technical mentors, we struggled to find the collaborative and interactive environment of creativity that I had come to expect as a part of our work together. My engagement with the group was unfolding not as a convener of inquiry, but rather as a technical assistant. I was there, as they saw my role, to assist them in learning digital video production skills.

After the first year the question arising within my practice and with this group was: what did this room of people share? What mattered? The work of using story as a form of narrative inquiry into what had meaning or import in their current lives still pulsed under the surface of their excitement of learning as they scanned photos from the past, heard their own voice on a recording, and manipulated photos through editing programs. But as the story mentor, the question of what was "framing" this work at Silver Harbour persisted the entire first year. We were neither co-creating new meanings, nor challenging our perceptions of each other or the world we shared. There was a desire on the part of the seniors to "produce" a story with production values that reflected what they had seen in mainstream media. The experience of the seniors, especially for the women, in mastering forms of digital technology and computers, was empowering. But from my perspective we were still engaged in a recreational activity.

Part of the challenge was the medium itself. It was a virtual world we were introducing to the seniors. The philosopher Albert Borgmann (1992) viewed the virtual world as having, in many ways, the same characteristics as a game, bounded by surfaces, limitless possibilities, and protected by boundaries. It was not vernacular art. Seeing "the hand of the maker" was viewed by most as a sign of the amateur and a disruption to the values of glamour associated with digital video productions. Mastering a digital video editing program within this senior's centre meant mastering the capacity to enhance and perfect past "pictures" of one's self and one's life.

The "real" world and its incumbent "worldliness" fraught with difficulties, was what Borgmann (1992) saw as a realm of "grace and misery" (p. 96). As the seniors hunched over their computers, re-creating their past, the "real" world was being replaced by the virtual world that, according to Borgmann, "is disposable, and discontinuous, and glamorous, and the sign of the perfect commodity" (p. 96). It was not vernacular 
art we were attempting to create here at Silver Harbour that first year, but rather something that was attempting to replicate what we were consuming all around us in mainstream media.

In the first year at Silver Harbour, the participants in the digital storytelling project were shaping new stories of past lives that attempted to be picture perfect. At the closing event of the program, the entire membership of the Silver Harbour Senior's Centre was invited to dress up and attend the "Oscars" where the participants in our group were given awards. Everyone enjoyed themselves. We all know the value of having fun and being recognized for one's work. Part of the joy of being challenged to create something is the how it is received, and the audience at Silver Harbour was gracious in its support. But despite the fun, this event, not unlike the attempts with the digital stories, was a replication of mass culture. In my role as artist within a communityengaged practice, at the end of this first year, I was still asking the question: what was the pedagogy embodied within the work? What learning emerged to remind us of what matters? And what, the reader might ask, do these questions have to do with The Night for All Souls?

\section{The Community-Engaged Arts Practice}

During this first year at Silver Harbour, I uncovered, buried away in a flowered cookie tin in the back of my bookcase, a collection of digital tapes that I had been avoiding. They were digital recordings I had made of the last moving images of my father alive. I started to work on these images of the past and created a short digital video with this material. I didn't know at the time why I was doing this. I taught myself a simple editing program and played with the images and the voice of my recently dead father, using the idea of memorial as a way to look at these living representations of him for the first time since my father's death. I titled it, A Postcard to the Beloved.

I start to think about using this short digital "postcard" as the material for a personal "digital shrine" at the next year's Night for All Souls. While working on this deeply personal and challenging work, I began to see the archival nature of this footage was in many ways similar in nature to the old photos some of the seniors at Silver Harbour were working with. In the second year of my residency I made the decision to extend the idea of making a digital video memorial into the community at Silver Harbour. What if we invited the seniors to produce a short digital "postcard" video to be part of a larger collective media installation for The Night for All Souls? Their digital stories seen as missives to a loved one, a beloved, who had passed away. 
I presented the idea of the media installation as a digital shrine. The intentions behind creating something that is described as a shrine was a shift in the way of thinking about media within this setting. My idea would challenge all of us to think beyond the recreational possibilities for our work together. I wanted to challenge the group members to think about a new venue for seeing their work and to how each individual postcard becomes part of a larger collective installation.

The media installation becomes the shrine. A shrine is created and approached with an attitude of reverence or reflection. By taking our digital stories out of the screening medium of computers and out of traditional public screenings with an audience, and placing them in an outdoor installation at night in a cemetery with candles, built artifacts, and the "changeableness" of weather, we would be asking the observer to interact with the media and its subjectivity in a very different way. This thinking of the work would be a way to re-imagine and evoke a different attitude to our work in the digital or virtual realities that we were encountering at Silver Harbour. In Albert Borgmann's (1992) thinking, I wanted to bring the glamorous commodious superficiality of digital media into the world of grace and heart, and lived experience.

When we asked the older adults at Silver Harbour if they would be willing to consider participating in this project, there was hesitation and some resistance. We decided we would work that fall creating individual digital postcards and decide afterwards about whether we wanted to take the work into a media art installation and public screening.

Creating the postcards in memory of a loved one changed the way in which we all worked together. People in the group started to share their feelings, the atmosphere in the room when we gathered each week to work together became quieter, and individual participants became less demanding in their need for attention. Something was shifting between the participants as first one, then another, chose to make pieces about people who had recently died and whom they were still grieving. Although it felt risky to ask the participants to consider death and dying in a Seniors Recreation Centre, as the weeks progressed the participants became more content with what they were trying to achieve with their own unique voices. It also changed how we viewed the work and for whom the work was being created. What happened that fall was a quiet deepening of their work individually, and a deepening of relationships with each other, as we shared the complexities of being alive and losing those we love. This was one of the outcomes of arts-based community engagement project that I had come to expect in working together. At Silver Harbour Seniors Centre, as we collectively began to see what we were producing together, we came to understand how the demands of creative work asks something from us. As difficult as the request was to ask 
seniors to contemplate and create a response to caring for the dead, their willingness to engage opened them to a new understanding of why the creative tensions art making can produce matters.

The group members that year persevered as they deepened their relationship to the stories they were creating. For one participant, the work changed a relationship with a sister in how they perceived a shared grandparent, for another it was the first time she could look at pictures of her mother and feel comforted. Many of these older adults chose to create a digital story about their grandparents. One started a piece as a memorial to the general idea of soldiers and then realized here was an opportunity to talk to something much closer, and created a memorial to a niece whom the family had yet to speak about and openly mourn. Collectively, we were producing meaning in the here and now. The creation of the digital shrine represented a pivotal moment in this community-engaged project for the seniors at Silver Harbour. And, after much discussion, they made a decision to include their digital postcards as a part of the collectively produced digital shrine in that year's Night of All Souls.

What became apparent to me over the course of the first two years at Silver Harbour may seem obvious to the reader. It was my personal creative and critical inquiry through creating memorials to my father in order to deal with his death that was fuelling my own arts-based inquiry. It was this creative inquiry that helped to determine the community-engaged art practice at Silver Harbour. This self-reflective art-based inquiry helps to fuel artists within community-engaged art projects and aid in their practice with community. Community-engaged art work is not ultimately about asking people to come together to make lanterns or produce digital stories, but rather about using these crafts or skills to facilitate creative inquiry within communities and people and to create meaning for ourselves together in the here and now. To make something that has not been made before, with each other and in support of each individual expression of that inquiry. The making of my father's memorial and my work at Silver Harbour were connected; I just didn't see it at the time.

As it turned out, the older adults at Silver Harbour used what they learned on how to express intimate expressions of memory through digital postcards in their next year's work on stories about the living. We needed the difficult challenge of working with our emotions and our grief in order to create meaningful exchanges. And in order to attend to the present, we needed to create an offering of remembrance to the past. This was not easy work, particularly in a Senior's Centre, where the loss of one's loved ones is all pervading and acute, but the rewards the community gained through this challenge have been worth it. As previously mentioned, many of the people in this group remain to this day working together and supporting one another as they age and tell stories. 
The greater public offering by artists Paula Jardine and Marina Szjarto becomes a calling to remind us of our temporal presence, and that to recognize and celebrate those who have died is to celebrate our presence, our lives, here and now.

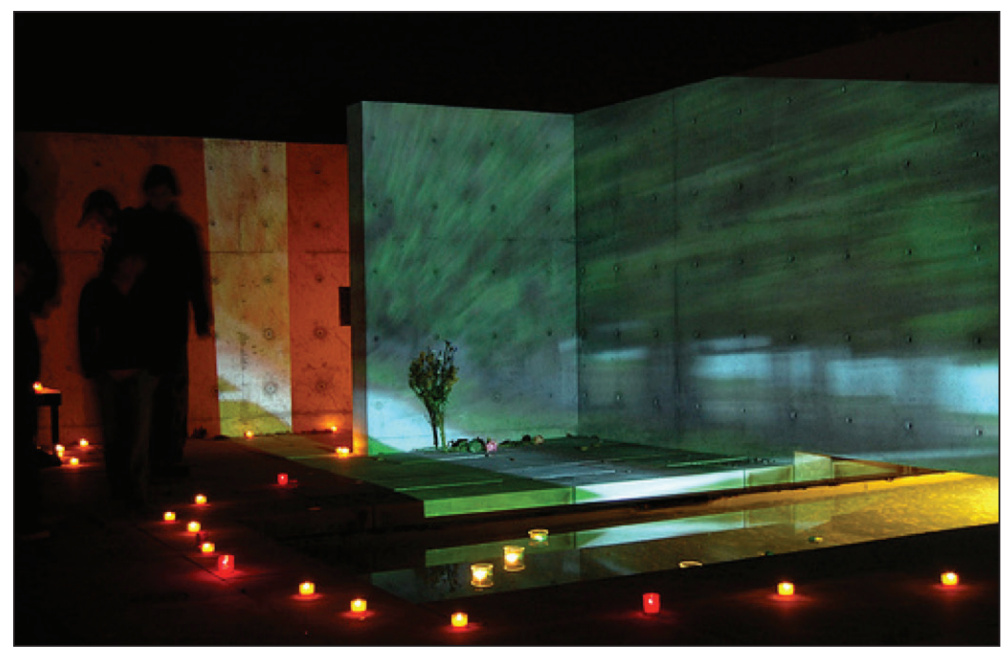

Fig. 1: Digital shrine - Mountain View Cemetery 2006 (photo by Patti Fraser)

For many years now at the end of October, we gather around. Another iteration of The Digital Shrine is projected into the dark night on the walls of Mountain View Cemetery's Hall of Celebration at The Night for All Souls. Lit by candles on the night of the event, we watch shadows of unknown strangers walk into the projections, and we are challenged into accepting that even the images of our beloved, no matter how intense our grief and longing, are like everything we know, ephemeral and ever changing. Composed of shadow and light, sounds echoing into the dark silence of the cemetery's night.

\section{References}

Borgmann, A. (1992). Crossing the postmodern divide. Chicago: Chicago University Press.
Mackey, C. (2010). Random acts of culture: Reclaiming art and community in the 21st century. Toronto, Ontario: Between the Lines. 


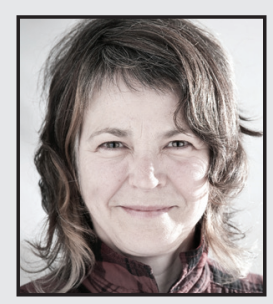

Patti Fraser, PhD, was the 2013 recipient of the Vancouver Mayor's Art Award for Community Engagement. She is a founding member of the Summer Visions Film Institute for Youth. Her community-engaged work has been recognized as best practice in the Chee Mah Muk Aboriginal Education with the BCCDC, and with the Canadian Council for Refugees. She was an artist-in-residence with the Arts, Health, and Seniors Research Project. Her most recent work, the 19th birthday party, was created in collaboration with Vancouver Foundation's Youth and Homelessness Initiative and she holds post-doctoral position with Simon Fraser's University's Art for Social Change Research Project. 